NASZA DERMATOLOGIA Online

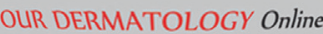

Source of Support: Nil

Competing Interests: None

\section{TREATMENT OF ACTIVE ACNE VULGARIS BY CHEMICAL PEELING USING 88\% LACTIC ACID}

\author{
Khalifa E. Sharquie ${ }^{1,2}$, Adil A. Noaimi ${ }^{1,2}$, Entesar A. Al-Janabi ${ }^{3}$ \\ ${ }^{1}$ Department of Dermatology, College of Medicine, University of Baghdad, Iraqi \\ ${ }^{2}$ Arab Board for Dermatology and Venereology, Baghdad Teaching Hospital, Medical \\ City, Baghdad, Iraq \\ ${ }^{3}$ Department of Dermatology and Venereology, Baghdad Teaching, Baghdad, Iraq
}

Corresponding author: Prof. Khalifa E. Sharquie

ksharquie@ymail.com

\begin{abstract}
Introduction: The etiopathogenesis of acne vulgaris is multifactorial, and its therapy is prolonged course that might be not accepted by many patients. Most recently TCA 35\% one session peeling gave complete clearance and full remission for active acne vulgaris. Lactic acid has been used effectively as therapeutic topical agents for many skin diseases.

Aim: To evaluate the efficacy and safety of chemical peeling using $88 \%$ lactic acid solution in the treatment of active acne vulgaris.

Material and Methods: This clinical, interventional, therapeutic study was done at the Department of Dermatology, Baghdad Teaching Hospital, during the period from October 2012 to October 2013.

Twenty five patients with active acne vulgaris were included, $15(60 \%)$ females and $10(40 \%)$ males and their ages ranged from 16-36 (21.5000 \pm 5.46279) years. Fifteen patients were associated with acne scars.

Three chemical peels using $88 \%$ lactic acid solution was carried out two weeks apart for patients with active acne vulgaris with or without scarring. Scoring for active acne vulgaris and acne scar was done for each case before and after operation to evaluate the severity of acne and the degree of scar before and after treatment.

All patients were with Fitzpatrick's skin types III and IV. Patients were followed up every two weeks during period of therapy and monthly for 3 months after stopping the treatment.

Results: Twenty five patients with active acne vulgaris were treated with 3 sessions of lactic acid, fifteen patients had associated acne scar. Scoring for active acne vulgaris including papules and pustules showed highly statistically significant reduction after 2 weeks of therapy $(p=0.0001)$, after 4 weeks $(p=0.0001)$ and after 6 weeks $(p=0.0001)$, with percent reduction $87.2 \%$ for papules and $94 \%$ for pustules after end of sessions while after 3 months follow up the reduction rate for papules $93.8 \%$ and $p$-value ( $\mathrm{p}=0.001$ ) and for pustules $97.6 \%$ and $(\mathrm{p}=0.0001$ ). While the scarring reduction was moderate in $3(20 \%)$ patients, marked in $3(20 \%)$ patients and excellent in $9(60 \%)$ patients with statistically significant reduction $(\mathrm{p}=0.002)$.

All patients had full satisfaction about the results of peeling. Post inflammatory hyperpigmentation was observed few weeks after peeling but follow up for 3 months showed complete clearance of pigmentation with lightening and tightening of skin.

Conclusions: Chemical peeling using $88 \%$ lactic acid is an effective mode of therapy for active acne vulgaris and acne scar in patient with dark complexion.
\end{abstract}

Key words: Chemical peeling; lactic acid; active acne vulgaris; acne scarring; dark complexion

Cite this article:

Sharquie KE, Noaimi AA, Al-Janabi EA. Treatment of Active Acne Vulgaris by Chemical Peeling Using 88\% Lactic Acid. Our Dermatol Online. 2014; 5(4): 337342 .

\section{Introduction}

Acne is a common chronic inflammatory skin disease experienced by most adolescents and young adults and the pathogenesis of acne vulgaris is a multifactorial. The four major identified factors that are involved in pathogenesis of active acne lesion formation and scarring are: excess sebum production, follicular epidermal hyperkeratinization, the proinflammatory effects of propioni bacterium acnes and other normal skin flora, and immunological reactions [1,2].

Although there are many topical and systemic agents that are used in treatment of acne vulgaris, still many patients don't use these therapies as the course of treatment is prolonged, other patients have no time to use drugs or they don't like to use it or they have phobia from their side effects [3-10]. Accordingly we are looking as a researcher for topical effective therapy that used for short time. 
Lasers have been used in treatment of active acne vulgaris but there is controversy regarding their effectiveness as one study showed using Diod laser is an effective therapy in clearing lesions by application three sessions, two weeks apart. Also, another study using Pulse Dye Laser (PDL) showed clearance of inflammatory acne vulgaris lesions using one session while another study also using Diod laser didn't show significant improvement of facial acne [11-15].

Most recently one session trichloracetic acid (TCA) peel $35 \%$ had been used effectively in treatment of active acne vulgaris with or without scarring and the result were very encouraging as induced both clearance of the lesions and remission of disease, In addition, scarring was reduced tremendously. This stimulated us to conduct the present work using lactic acid $88 \%$ in treatment of active acne vulgaris [16-20].

Lactic acid is a member of alpha hydroxy acids (AHA) which has been used in treatment of many skin diseases [21] including: Lactic acid used in treatment of recurrent aphthous ulcer as oral gurgle by increasing spontaneous secretion of endothelial growth factor from keratinocytes and by its antibacterial action [22].

Also, lactic acid has antioxidant action and this might help in repigmentation of patch of vitiligo as topical 15\% lactic acid solution has been use as new mode of therapy for the treatment of localized type of vitiligo [23].

Lactic acid cream $6 \%$ has been found effective in the treatment of melasma as topical therapy and also LA $88 \%$ has been tried as effective peeling agents for melasma [24]. Topical 15\% lactic acid solution was found to be an effective therapy for alopecia areata [25].

The two major side effects of alpha hydroxy acids are irritation and sun sensitivity [26].

Hence, the aim of present work is to treat patients with active acne vulgaris with associated scars by $88 \%$ lactic acid as peeling agents and to compare its efficacy with TCA35\% peels.

\section{Material and Methods}

This clinical, interventional, therapeutic study was carried out at the Department of Dermatology, Baghdad Teaching Hospital, during the period from October 2012 to October 2013. Twenty five patients with active acne vulgaris were included in this study, $15(60 \%)$ females and $10(40 \%)$ males and their ages ranged from 16-36 with mean and SD of 21.5000 \pm 5.46279 years. Fifteen patients were associated with acne scars 10 (66.6\%) females and 5 (33.4) males.

The nature and target of this study were explained for each patient and formal consent was taken for each patient before starting the therapy, after full explanation about the nature of the disease, course, the procedure of treatment, follow up, prognosis and the need for pre and post treatment photographs by SonyDigital, high sensitivity, 16.1megapixels, $5 \mathrm{x}$ optical zoom camera in the same place with fixed illumination and distance. Also, ethical approval was given by the scientific committee of the Scientific Council of Dermatology and Venereology-Iraqi Board for Medical Specializations. Statistical analysis was carried out using $\mathrm{T}$ test and Chi square.

History and dermatological examination were performed for all patients regarding all demographic points related to the disease. The severity of acne was graded using the following score:

- Mild acne in which the count of pustules is less than 20 and the count of papules is less than 10 .
- Moderate acne in which the count of pustules is ranging between 20-40 and the count of papules is ranging between 1030 .

- Severe acne in which the count of pustules is more than 40 and the count of papules is more than 30 .

Patients who had scarring in addition to active lesions the following score was used to evaluate the severity of scarring before and after peeling:

Score $0=0 \quad$ No change or baseline.

Score $1=1 \%-25 \% \quad$ Mild reduction.

Score $2=26 \%-50 \%$ Moderate reduction.

Score $3=51 \%-75 \%$ Marked reduction.

Score $4>75 \%-100 \%$ Excellent reduction.

Patients satisfaction to response to therapy was evaluated according to satisfaction score that classified into:

1) Full satisfaction. 2) Partial satisfaction. 3) No satisfaction.

In addition to active lesions, some patients had white and black comedones. All patients were with Fitzpatrick's skin types III and IV.

Exclusion criteria are coexistence of any other dermatoses involving the face and allergy to medications, plus patients who had used any topical and systemic treatments in the previous one month, pregnant and lactating women, recurrent herpes infection, immunocompromised patients, diseases or drugs that interfere with clotting systems, patients with medical diseases like diabetes mellitus, epilepsy and patients with other types of acne like drug induced acne, cosmetic acne, post-hair epilation acne, occupational acne, peri-oral dermatitis, mechanical acne, and acne aestivalis.

\section{Technique of peeling}

Lactic acid (GAINLAND CHEMICAL COMPANY, UK) was used in concentration of $88 \%$. Patients were prepared by cleansing and degreasing the whole face by using acetone or $70 \%$ alcohol soaked-gauze. The area was rubbed vigorously until it losses the greasy texture and becomes dry with faint erythema. Then the whole face was coated with lactic acid by using cotton-tipped applicator and generally rubbed in with pressure, and number of coating ranged from 1 - 3 applications with a mean 2, with three minutes apart, until fine frosting occurred. Three sessions of lactic acid peel was done for all 25 patients of active acne, even patients with scars, two weeks apart.

\section{Post operative instructions and follow up}

The skin of the treated area was washed with water immediately after the procedure, then cold wet compresses were applied immediately after the peel. After that hydrocortisone $1 \%$ ointment or zinc oxide ointment was applied for whole face. Patients were told that stinging will crescendo for 2 minutes and then will subside. All patients were given instruction leaflets that also specify dates for the patients follow up visit. For the entire first week, the patient is instructed to use topical fusidic acid (Leo-Pharma Company) ointment and systemic antibiotic include Augmentin (amoxicillin/ clavulanate potassium) $625 \mathrm{mg}$ /3times daily. In addition antihistamine were prescribed for patients, we asked the patients to wash the face 3-4 times/day with potassium permanganate solution (1/10000) or using an acetic acid solution (1 tea spoon white vinegar in 1 pint warm water) in the first five days following peeling. 
And after five days onward, the patient could resume washing the face and scalp with non irritant soap and water. Also, the patients were advised to use sun screen at morning, this sunscreen contains titanium dioxide (ISIS, MADE IN FRANCE) and topical hydrocortisone at night. Follow up after 6 weeks, follow up was carried for 3 months to monitor the clearance of lesions and improvement in the scars and any relapse.

\section{Results}

Lactic acid peeling was used three times 2 weeks a part in patients with active acne vulgaris and scarring. Scoring for active acne vulgaris included papules and pustules showed highly statistically significant reduction after 2 weeks of therapy $(p=0.0001)$, after 4 weeks $(p=0.0001)$, after 6 weeks $(p=0.0001)$ with percent reduction $87.2 \%$ for papules and $94 \%$ for pustules after end of sessions while after 3 months follow up the reduction rate for papules $93.8 \%$, $p$-value $(\mathrm{p}=0.001)$ and for pustules $97.6 \%$, $p$-value ( $\mathrm{p}=0.0001$ ), (Tabl I).

While the acne scar scoring reduction after 3 sessions of therapy was ranged from $26-50 \%$ in 3 patients (moderate reduction) and $51-75 \%$ in 3 patients (marked reduction), while was more than $75 \%$ in 9 patients (excellent reduction), with statistically significant reduction $(\mathrm{p}=0.002)$ following peeling. There was mild post inflammatory hyperpigmentation. After 3 months of follow up the reduction of scars was not significantly different from the time after sessions but there was obvious tightening and whitening of the skin of whole face (Tabl. II).

\begin{tabular}{|c|c|c|c|c|c|c|c|}
\hline & Pre therapy & $\begin{array}{c}\text { (2nd visit) } \\
\text { 1st session }\end{array}$ & $\begin{array}{c}\text { (3rd visit) } \\
\text { 2nd session }\end{array}$ & $\begin{array}{c}\text { (4th visit) } \\
\text { 3rd session }\end{array}$ & $\begin{array}{c}\text { Percent } \\
\text { redution** }\end{array}$ & Follow up & $\begin{array}{c}\text { Percent } \\
\text { redution** }\end{array}$ \\
\hline papule & $33.7 \pm 14.5$ & $13.1 \pm 4.1$ & $7.2 \pm 2.1$ & $3.7 \pm 1.9$ & $87.2 \%$ & $2.1 \pm 0.8$ & $93.8 \%$ \\
\hline *p- value & & 0.0001 & 0.0001 & 0.0001 & & 0.001 & \\
\hline pustule & $33.1 \pm 10.7$ & $13.6 \pm 5.1$ & $6.5 \pm 2.2$ & $2 \pm 0.9$ & $94 \%$ & $0.8 \pm 0.6$ & $97.6 \%$ \\
\hline P- value & & 0.0001 & 0.0001 & 0.0001 & & 0.0001 & \\
\hline
\end{tabular}

Table I. Results of patients with active acne vulgaris that was treated by $88 \%$ lactic acid peels. *Percent Reduction $=(A-B) / A * 100$,Ais an initial value, $B$ is a final value

\begin{tabular}{|c|c|c|c|}
\hline Reduction rate & No. of patients & $\%$ & P value \\
\hline Excellent (75-100\%) & 9 & $60 \%$ & \multirow[t]{3}{*}{0.002} \\
\hline Marked (51-75\%) & 3 & $20 \%$ & \\
\hline Moderate (26-50\%) & 3 & $20 \%$ & \\
\hline Total & 15 & 100 & \\
\hline
\end{tabular}

Table II. Results of peeling of scarring that associated with acne lesions.

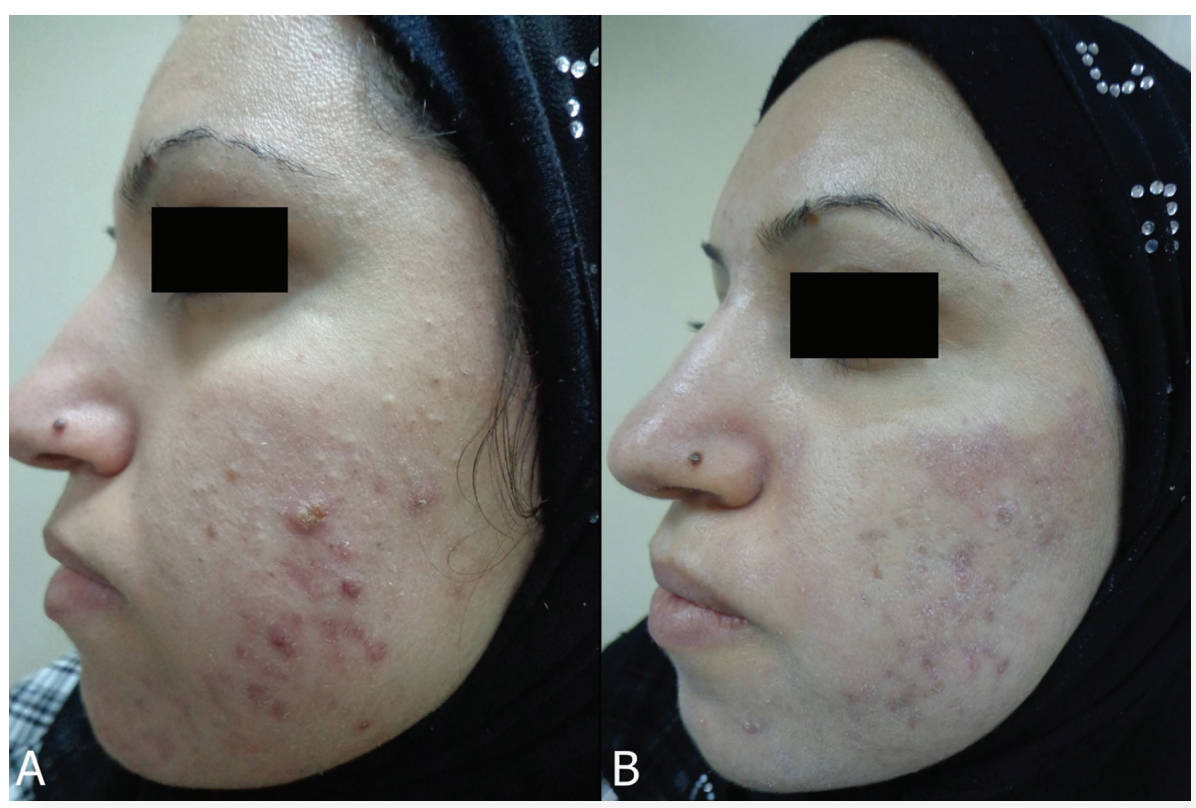

Figure 1. Twenty four years old female with active skin lesions. (A) Before treatment; (B) Showing clearance of active lesions after $88 \%$ lactic acid peels. 


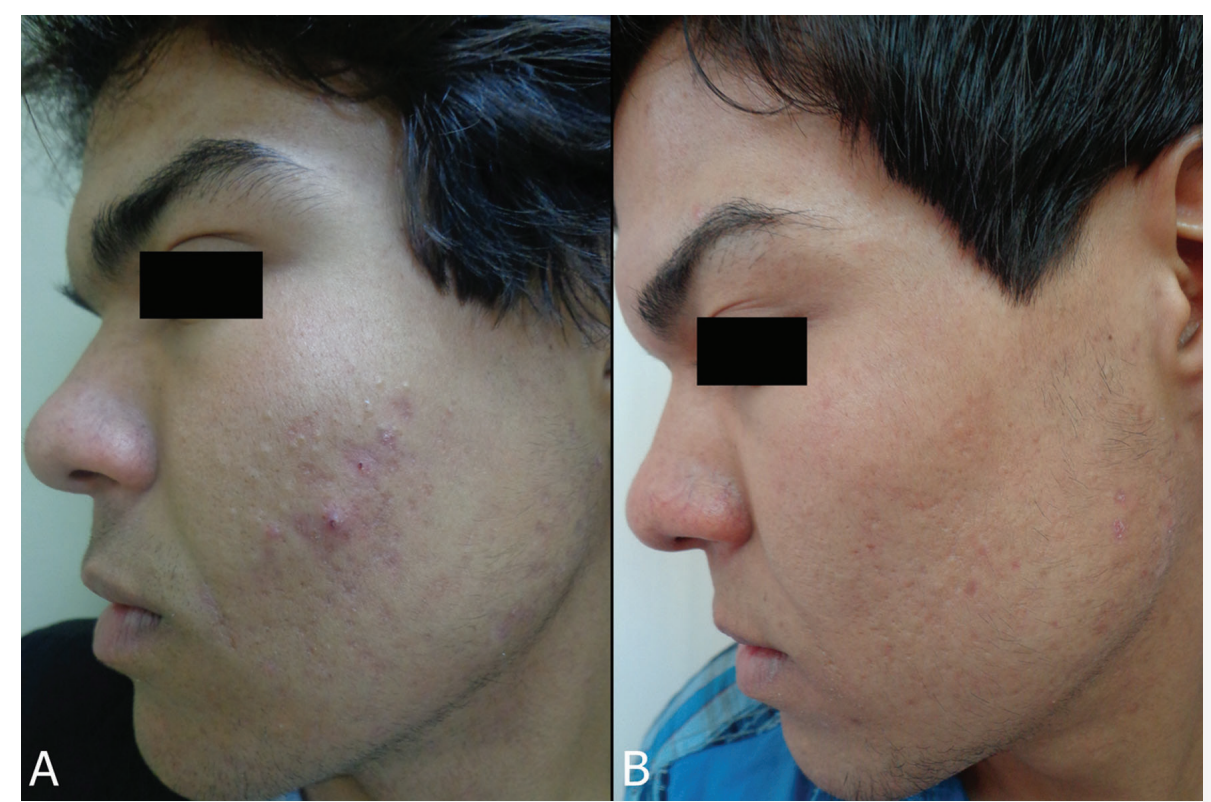

Figure 1. Twenty four years old female with active skin lesions. (A) Before treatment; (B) Showing clearance of active lesions after $88 \%$ lactic acid peels.

\section{Discussion}

There are many therapies for active acne vulgaris for clearance of lesions and preventing scars but all of these need long term of treatment at least 6 months. Still there are many non compliant patients for many reasons mainly because there are not ready to use treatment for long time or they are afraid from their side effects [3-8]. Accordingly researcher are looking for single therapy that used over short time in order to induce recovery from active lesions.

Laser sessions are effective for acne scars but give controversial results in treatment of active acne vulgaris in addition its high cost therapy and not available in centers [11-15].

Most recently, TCA 35\% had been used in treatment of active acne vulgaris and the result very satisfactory for patients in inducing long term remission of acne lesions and reducing scarring [20].

The present work using $88 \%$ LA showed significant improvement of active acne vulgaris including papules and pustules after 3 session of peeling in patients with active acne lesion and the associated scarring was effectively reduced.

When the result of peeling of TCA compared with peeling result of lactic acid, we observed almost similar result both in the clearance of active lesions and reducing of scars at the end of course of therapy and at the end of 3 months follow up (Tabl. III).

Accordingly one session of TCA peeling is as effective as 3 sessions of lactic acid.

Hence the present study showed that LA peeling is a cost effective therapy for treatment of active acne vulgaris and its associated scarring that could be advised as treatment for patients that they don't like to use topical and oral therapy in a long term regimen.

Dermabrasion and peeling by lasers or acids are not well advised in patients with dark complexion as post inflammatory hyperpigmentation might be complication of these therapy but we have noticed from daily clinical practice that postinflammatory hyperpigmentation is not a complications of dermabrasion or peeling although all our patients have Fitzpatrick's skin types III and IV. In contrary these patients have whitening of their skin [18-20].

It is difficult to explain the mechanism of action of lactic acid peeling but we can suggest through the following actions: through reduction of microflora of acne lesions mainly Propioni bacterium acnes and other bacteria that causing acne, also might reduce the size of sebaceous glands that is involved in pathogenesis of the acne and thirdly LA might change the immunological reaction present in the acne lesions hence inducing clearance of lesions and reducing the scars.

In conclusion, lactic acid $88 \%$ peels is low cost mode of therapy for active acne vulgaris and associated scarring with no complications.

\section{REFERENCES}

1. William J, Harald PM. Acne diagnosis and management. Martin Dunitz Ltd, 1st ed, London, 2001;1-37.

2. Sommkr S, Bojar R, Cunliffe WJ, Hollanixf D, Holland KT, Naags $\mathrm{H}$. Investigation of the mechanism of action of $2 \%$ fusidic acid lotion in the treatment of acne vulgaris Clin Exp Dermatol. 1997;22:211-5. 3. Ellis C, Krach K. Uses and complications of isotretinoin therapy. J Am Acad Dermatol. 2001;45:S150-7.

4. Leyden J. Current issues in antimicrobial therapy for the treatment of acne. J Eur Acad Dermatol Venereol. 2001;15(suppl 3):51-5.

5. Eaden E, Jones C, Tipper J, Cove J, Cunliffe W, Layton A. Antibiotic resistant propionibacteria in acne: need for policies to modify antibiotic usage. BMJ. 1993;306:555-6.

Leyden J, Shalita A. Rational therapy for acne vulgaris: an update on topical treatment. J AmAcad Dermatol. 1986;15:907-14.

7. Eady EA, Cove JH, Holland KT, Cunliffe WJ. Erythromvcin resistant propionibacteria in antibiotic treated acne patients: association with therapeutic failure. Br J Dermatol. 1989;121:51-7.

8. Leyden JJ, McGinley KJ, Cavalieri S, Webster GF, Mills OH, Kligman AM. Propionibacterium acnes resistance to antibiotics in acne patients. J Am Acad Dermatol. 1983;8:41-5. 


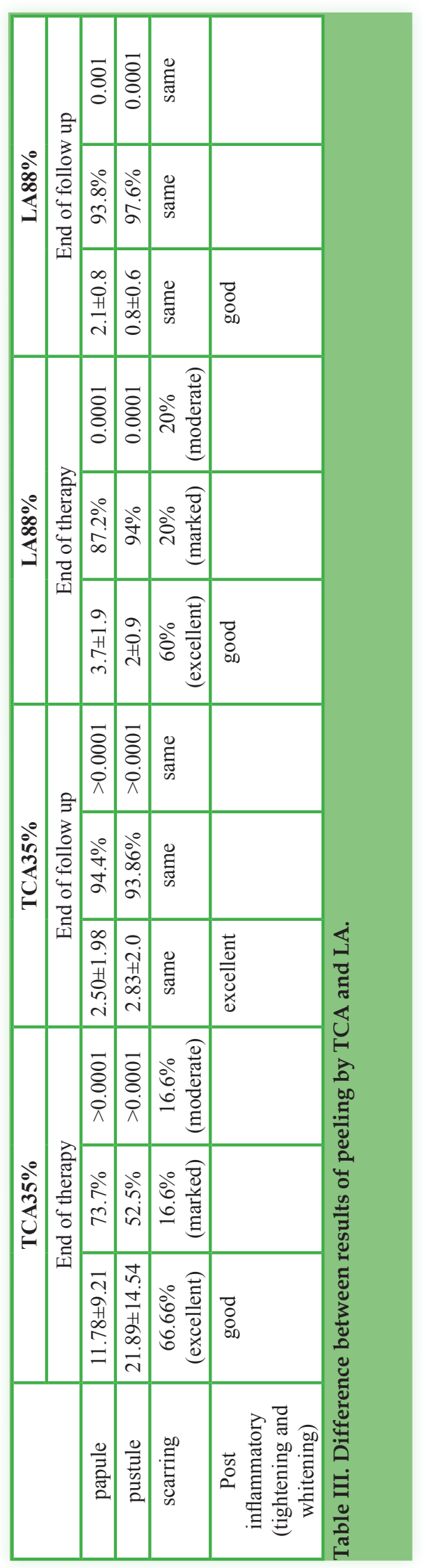


9. Zaenglein AL, Thiboutot DM. Acne Vulgaris. Bolognia JL, Jorizzo JL, Schaffer JV. Dermatology, 3rd ed., China: Elsevier Saunders. 2012;36:545-60.

10. James WD, Berger TG, Eleston DM (eds.) Acne.Andrew's diseases of the skin Clinical Dermatology 11thed., Philadilphia: Saunders Elsevier. 2011;13:228-46.

11. Jacob CI, Dover JS, Kaminer MS. Acne scarring: a classification system and review of treatment options. J Am Acad Dermatol. 2001;45:109-17.

12. Moritz DL. Surgical corrections of acne scars. Dermatol Nurs. 1992;4:291-9.

13. Seaton ED, Charakida A, Mouser PE, Grace I, Clement RM, Chu AC. Pulsed-dye laser treatment for inflammatory acne vulgaris: Randomised controlled trial. Lancet. 2003;362:1347.

14. Orringer JS, Kang S, Hamilton T, Schumacher W, Cho S, Hammerberg C, et al. Treatment of acne vulgaris with a pulsed dye laser: A randomized controlled trial. JAMA. 2004;291:2834.

15. Friedman PM, Jih MH, Asadi AK, Goldberg LH. Treatment of inflammatory facial acne vulgaris with 1450-nm Diode laser :Apilot study. Dermatol Surg. 2004;30:147-51.

16. Garg VK, Sinha MS, AND Sarkar R. Glycolic Acid Peels Versus Salicylic-Mandelic Acid Peels in Active Acne Vulgaris and PostAcne Scarring and Hyperpigmentation: A Comparative Study 2008 by the American Society for Dermatologic Surgery, Inc. _ Published by Wiley Periodicals, Inc._ ISSN: 1076-0512 _ Dermatol Surg. 2009;35:59-65.

17. Atzori L, Brundu MA, Biggio P, Orru A. Glycolic acid peeling in the treatment of acne. J Eur Acad Dermatol Venereol. 1999;12:119 22.

18. Al-Waiz MM, Al-Sharqi AI. Medium depth chemical peels in treatment of acne scars in dark-skinned individuals. Dermatol Surg. 2002;28:1-5.

19.Sh arquie KE, Noaimi AA. CO2 dermabrasion of acne scarring. J Iraqi Comm Mede. 2013;25:1.
20. Sharquie KE, Noaimi AA, Al-Janabi EA. Treatment of Active Acne Vulgaris by Chemical Peeling Using TCA 35\%: J Cosm Dermatol Scienc Applicat. 2013;3:32-5.

21. Fox M, Helfrich Y, Kang S. Other topical medications in: In Bolognia JL,Jorizzo JL and Schaffer JV. Dermatology, 3rd ed., Spain: Mosby Elsevier 2012;129:2158.

22. Sharquie KE, AL-Tammimy SM. Lactic Acid 5\% Mouthwash in the Treatment of Recurrent Aphthous Ulcerations. A Thesis Submitted To The Scientific Council Of Dermatology And Venereology As A Partial Fulfillment For The Degree Of Fellowship Of Iraqi Board For Medical Specialization In Dermatology And Venereology, coll. Med. Bagh. University. 2005.

23. Sharquie KE, Mohammed Y Saeed. Treatment of vitiligo with $15 \%$ lactic acid solution in comparison with other topical therapies in vitiligo.Thesis for fellow ship of Iraqi commission for medical specialization in Dermatology and Venereology, coll. Med Bagh Univ. 2002:36-46.

24. Sharquie KE, Al-Mashhadani SA, Al-Saadi AF. Topical Treatment of Melasma with Lactic Acid Cream: A comparative study with Glycolic Acid Cream. A Thesis Submitted to the Scientific Council of Dermatology and Venereology as a Partial Fulfillment for the Degree of Fellowship of Iraqi Board for Medical Specializations in Dermatology, coll. Med Bagh Univ. 2006.

25. Al-waiz MM, Al Mashhadani SA, Qadir NO. Treatment of patchy alopecia areata by using topical $15 \%$ lactic acid solution" is submitted to the Scientific Committee of Dermatology and Venereology as a partial fulfillment for the degree of Fellowship of Iraqi Board for Medical Specialization in Dermatology, coll. Med Bagh Univ. 2006. 26. Draelos ZD.Cosmotics and cosmeceuticals in: In Bolognia JL,Jorizzo JL and Schaffer JV. Dermatology, 3rd ed., Spain: Mosby Elsevier. 2012;153:2488.

Copyright by Khalifa E. Sharquie, et al. This is an open access article distributed under the terms of the Creative Commons Attribution License, which permits unrestricted use, distribution, and reproduction in any medium, provided the original author and source are credited. 